REVISTA DE GESTÃO E SECRETARIADO

MANAGEMENT AND ADMINISTRATIVE

PROFESSIONAL REVIEW

ISSN: 2178-9010
Revista GeSec

São Paulo, SP, Brasil

v. 12 , n. 1, p. 106-132

jan. /abr. 2021

DOI: http://dx.doi.org/10.7769/gesec.v12i1.1224

\title{
Dinâmica de engajamento em equipes de projetos
}

\section{Dynamics of engagement in project teams}

Luan David Pereira Nascimento ${ }^{1}$

Thiago Oliveira ${ }^{2}$

Josué Vitor Medeiros Junior ${ }^{3}$

André Morais Gurgel ${ }^{4}$

\section{Resumo}

A presente pesquisa busca analisar a dinâmica do engajamento de membros de uma equipe em um projeto de estruturação de um Parque Tecnológico, ligado a uma instituição pública federal de ensino superior. Com base na metodologia da Dinâmica de Sistemas, investigou-se as percepções dos membros sobre as atividades executadas e o desempenho da equipe ao longo do ciclo de vida do projeto. As entrevistas semiestruturadas com os membros do projeto orientado pelo modelo JD-R (Job Demands-Resources) foram realizadas, transcritas e codificadas, através da análise de discurso e conteúdo. Como resultado, foi elaborado um diagrama causal com a estrutura básica de feedbacks, representando a dinâmica relacionada a este fenômeno de engajamento e os seus fatores relacionados. Os resultados demonstram que o engajamento dos membros da equipe está ligado a enlaces causais de reforço creditados ao reconhecimento e a execução das práticas de gestão de projetos. Além disso, sofre ainda influências de enlaces de equilíbrio relacionados a dificuldade de conciliar as demandas do projeto com as atribuições diárias, a falta de apoio da chefia imediata e os impedimentos surgidos durante a execução das atividades do projeto. Dessa forma, medidas de aperfeiçoamento para alavancar o engajamento são propostas.

\footnotetext{
${ }^{1}$ Mestre em Gestão de Processos Institucionais, Administrador na Universidade Federal do Rio Grande do Norte (UFRN).

${ }^{2}$ Mestrando no Programa de Pós-graduação em Administração da UFRN.

${ }^{3}$ Doutor em Administração, Pró-reitor de Planejamento e Coordenação Geral na UFRN.

${ }^{4}$ Doutor em Engenharia de Produção, Secretário de Gestão de Projetos na UFRN.
} 
Palavras-chave: Engajamento de Equipes. Gestão de Projetos. Dinâmica de sistemas.

\begin{abstract}
This research analyzes the team members engagement dynamics in a project to structure a Technological Park, linked to a federal public institution of higher education. Based on the Systems Dynamics methodology, members' perceptions about the activities performed and the team's performance throughout the project's life cycle were investigated. The semi-structured interviews with the project members guided by the JD-R (Job Demands-Resources) model were carried out, transcribed and coded, through discourse and content analysis. As a result, a causal diagram with the basic feedback structure was drawn up, representing the dynamics related to this engagement phenomenon and its related factors. The results demonstrate that the engagement of team members is linked to reinforcement loops credited to the recognition and execution of project management practices. In addition, it is also influenced by balancing loops related to the difficulty of reconciling the demands of the project with the daily activities, the lack of support from the immediate management and the impediments that arise during the execution of the project activities. In this way, improvement measures to leverage engagement are proposed.
\end{abstract}

Keywords: Teams Engagement. Project Management. Systems Dynamics

\title{
Introdução
}

As pessoas são elementos centrais para o alcance de objetivos organizacionais (Liu \& Cross, 2016; Han \& Beyerlein, 2014). No contexto da gestão de projetos, diversos autores têm enfatizado a relevância das pessoas envolvidas no projeto para o alcance dos objetivos e sucesso dos projetos, dada sua efetividade para lidar com demandas organizacionais que têm um escopo maior do que a capacidade de resolução por um só indivíduo (Cooke-Davies, 2002; Kerzner, 2006; Andersen, Birchall, Jessen \& Money, 2006; Carvalho, Patah \& Bido, 2015; Hsu \& Sun, 2017; Liu \& Cross, 2016).

Nesse contexto, cada vez mais têm sido compreendidos o engajamento como fator que impulsiona o desempenho das equipes nos projetos (Matthews, Stanley \& Davidson, 2018), focando em questões como a busca pelos seus antecedentes e fatores responsáveis pelo engajamento no ambiente organizacional (Shuck, Rocco \& Albornoz, 2011).

Além disso, lacunas são identificadas em pesquisas quanto ao tema, tendo em vista a

Revista Gestão e Secretariado (GeSec), São Paulo, SP, 12(1), jan./abr., 2021, p. 106-132. 
significativa atenção para os aspectos característicos do sucesso dos projetos e da relação de confiança entre membros (Bond-Barnard, Fletcher \& Steyn, 2018; Tuuli, 2018; Hsu et al., 2017; Henderson, Stackman \& Lindekilde, 2016) e pouco enfoque

em fatores que impulsionam as equipes de projetos, como o engajamento (Matthews et al., 2018).

Ainda assim, a literatura sobre o tema parece estar ao nível de mensuração individual. Nesta perspectiva, pesquisas futuras devem observar as construções coletivas, como as equipes (Bailey, Madden, Kerstin, \& Fletcher, 2017; Matthews et al., 2018), o que gera uma lacuna de pesquisa, especialmente em equipes de projetos, tema ainda pouco explorado (Matthews et al., 2018).

O modelo de demandas e recursos de trabalho (JD-R, na sigla em inglês) surge para explicar como o engajamento se comporta nas organizações (Demerouti, Bakker, Nachreiner, \& Schaufeli, 2001; Bakker \& Demerouti, 2007). Em síntese, o modelo explicita que os recursos de trabalho (recompensas financeiras, por exemplo) foram identificados como preditores do engajamento no trabalho. Já as demandas de trabalho (esforço para se executar tarefas, por exemplo) causariam estresse e fadiga (Salanova, Agut \& Peiró, 2005; Richardsen, Burke \& Martinussen, 2006; Koyuncu, Burke \& Fiksenbaum, 2006). É por meio da interação desses fatores que o engajamento se manifesta.

Abordado sob uma perspectiva dinâmica, o fenômeno do engajamento pode favorecer uma melhor compreensão sobre os fatores envolvidos no seu surgimento e desenvolvimento.

Assim, questões como estas podem ser abordadas em uma perspectiva sistêmica e dinâmica (Sterman, 2000). Tal lógica é baseada na construção de estruturas caracterizadas pela retroalimentação para compreender como o objeto investigado se comporta. (Bala, Arshad $\&$ Noh, 2016).

Nessa perspectiva, encontra-se uma determinada instituição federal de ensino superior (IFES), que está desenvolvendo projetos para a implementação de um Parque Tecnológico, o qual está localizado no entorno da instituição. Nesses projetos, a participação dos colaboradores nas equipes dos projetos é voluntária - geralmente são os servidores da IFES que participam dos projetos - e não há qualquer tipo de retribuição vinculada aos resultados do projeto.

Foi identificado que o desempenho dessas equipes não é uniforme e constante ao longo do ciclo de vida do projeto. Dessa forma, entender como esse tipo de fenômeno se comporta exige uma abordagem que abarque a dinamicidade, ou seja, como o fenômeno em investigação se comporta ao longo do tempo, neste caso, o engajamento dos membros das equipes destes 
projetos.

Propõe-se, então, a utilização da metodologia Dinâmica de Sistemas, utilizada para compreender sistemas complexos, o inter-relacionamento entre variáveis em que ciclos de enlaces são responsáveis pelo comportamento do sistema em análise como forma de identificar quais fatores influenciam no engajamento em equipes de projetos.

O pensamento sistêmico consiste na capacidade de compreender que as ações não são isoladas; pelo contrário, relacionam-se entre si e possuem consequências, culminando em determinados resultados. Sob esse prisma, Bala et al. (2016) afirmam que uma possível solução está em utilizar uma metodologia baseada em estruturas de retroalimentação para compreender como o objeto investigado se comporta.

Nesse contexto, considerando o engajamento, fenômeno de natureza complexa, o presente artigo pretende investigar a seguinte questão de pesquisa: qual a dinâmica do engajamento em uma equipe de projeto? Dessa forma, o objetivo da presente pesquisa é identificar como o fenômeno do engajamento ocorre em uma equipe de projeto no contexto de um Parque Tecnológico de uma IFES à luz da teoria JD-R e da Dinâmica de Sistemas.

A presente pesquisa justifica-se pela possibilidade de criação de um modelo para a compreensão do engajamento em equipes de projetos, tema ainda pouco explorado na literatura. Contudo, esse trabalho está organizado da seguinte forma: introdução sobre o tema; referenciais teóricos sobre o engajamento e modelo de recursos e demandas de trabalho e gestão de projetos; método e procedimentos metodológicos; resultados e discussões; e conclusões da pesquisa.

\section{Engajamento e Modelo de Recursos e Demandas de Trabalho}

O trabalho contemporâneo no contexto das organizações modernas exige, por parte dos gestores, novas formas de análise para se compreender e aperfeiçoar o processo de sinergia entre as equipes. Nas últimas décadas, o papel dos indivíduos em organizações com as mesmas condições de trabalho pode diferir substancialmente, o que chama atenção para alguns aspectos que impactam no desempenho dessas equipes (Ilgen \& Hollenbeck, 1991; Lyons, 2008).

Conceitualmente, equipes são compostas por duas ou mais pessoas com um objetivo específico, onde cada membro responde por um papel e possui responsabilidades, em forma de interação e dinâmica específica (Salas, Dickinson, Converse, \& Tannenbaum, 1992). Um constructo relevante diretamente relacionado com o nível de aderência das equipes com as suas atividades, bem como ligado ao bom desempenho frente às demandas de trabalho dessas equipes é o engajamento (Macey \& Schineider, 2008; Bakker \& Bal, 2010). 
O Engajamento pode ser descrito como um estado afetivo e cognitivo que envolve os estados de vigor, dedicação e absorção (Schaufeli, Salanova, González-Romá, \& Bakker, 2002; Costa, 2008; Leiter \& Bakker, 2010; Costa, Passos \& Bakker, 2014; Mcclelland, Leach, Clegg, \& Mcgowan, 2014). No ambiente de trabalho, o termo relaciona-se com a vivência de um estado de entusiasmo, envolvimento e comprometimento com as atividades laborais, sobretudo com a tendência de aceitação, por parte do membro, de novos desafios (Gkorezis, Bellou, Xanthopoulou, Bakker, \& Tsiftsis 2016).

Estudos propõem a relação entre engajamento dos colaboradores e o aumento da produtividade nas organizações (Demerouti \& Bakker, 2011; Costa et al., 2014; Mcclelland et al., 2014). Há também evidências entre o engajamento e o aumento de recursos financeiros (Xanthopoulou, Bakker, Demerouti, \& Schaufeli, 2007), a satisfação dos clientes (Salanova, Agut \& Peiró, 2005) e a diminuição da rotatividade nas organizações (Shuck, Reio \& Rocco, 2011).

Pressupõe-se, então, que a promoção do engajamento do indivíduo é condição essencial para se estudar a dinâmica do engajamento em equipes (Reijseger et al., 2013). Para entender quais variáveis interferem no engajamento, Bakker, Demerouti and Euwema (2005) propuseram um modelo denominado modelo de demandas e recursos de trabalho. O modelo JD-R demonstra como os recursos de trabalho e os recursos pessoais interferem no engajamento do trabalho, e como as demandas de trabalho moderam a relação entre recursos de trabalho e engajamento (Albrecht, 2010).

As demandas de trabalho são aspectos ou características do trabalho que exigem esforço físico ou psicológico - cognitivo e emocional por parte do trabalhador, estando associados a certos custos fisiológicos ou psicológicos (Bakker et al., 2005). Exemplos podem ser listados, como a pressão do trabalho, a sobrecarga de papéis, a insegurança da manutenção do emprego e as condições do ambiente de trabalho como exemplos que expressam as demandas de trabalho (Grover, Teo, Pick, \& Roche, 2017). Estas são características negativas do trabalho que levam à fadiga, conflitos com colegas de trabalho, incertezas com relação a manutenção do emprego e a sobrecarga de trabalho (Schaufeli \& Taris, 2014).

Os recursos do trabalho estão relacionados a estrutura proporcionada pela organização (físicas, sociais ou organizacionais) que aliviam, diminuem ou suavizam o impacto da demanda de trabalho do colaborador, pois direcionam o funcionário para as metas organizacionais e estimulam o crescimento pessoal (Schaufeli \& Bakker, 2003; Leiter \& BakkerMA, 2010).

Leiter and Bakker (2010) citam como exemplos de recursos de trabalho a autonomia Revista Gestão e Secretariado (GeSec), São Paulo, SP, 12(1), jan./abr., 2021, p. 106-132. 
que é delegada ao empregado, o apoio social dos pares na execução das atividades, suporte da chefia imediata, recompensas financeiras e a complexidade de habilidades que são empregadas no decurso dos processos de trabalho.

Pesquisadores aduzem que esses recursos promovem uma motivação intrínseca no colaborador e reforçam a sensação de crescimento, aprendizado e desenvolvimento profissional (Bakker, 2011; Quiñones, Broeck \& Witte, 2013). Um processo de retroalimentação adequado estimula o aprendizado e o aumento da experiência profissional, enquanto uma margem de flexibilidade para tomada de decisão permite o crescimento e o desenvolvimento profissional do trabalhador (Bakker, 2011).

O apoio realizado pelos pares, por exemplo, tende a aumentar a probabilidade de concluir ações no trabalho com êxito (Demerouti \& Bakker, 2011). Em ambas as modalidades, os recursos tendem a criar um efeito positivo e o engajamento é provável de ocorrer (Schaufeli \& Bakker, 2003; Lewig, Xanthopoulou, Bakker, Dollard, \& Metzer, 2007).

Bakker, Demerouti and Sanz-Vergel (2014) assumem que os recursos de trabalho e as demandas de trabalho são dois processos separados e independentes, ou seja, um processo leva ao prazer no trabalho, motivação e engajamento no trabalho e, por via de consequência, ao aumento da performance no trabalho; o outro a exaustão, lesões, a deterioração na saúde e a diminuição da performance.

Nesse contexto, compreender a dinâmica do engajamento em equipes adquire relevância, uma vez que o engajamento dos seus membros é importante para o equilíbrio da equipe, para execução de tarefas e para o alcance dos objetivos organizacionais (Macey \& Schineider, 2008; Bakker \& Bal, 2010).

\section{Gestão de Projetos}

Um projeto pode ser entendido como um esforço encadeado em um conjunto de etapas com o objetivo de criar um produto, serviço ou resultado singular, de forma temporária, conforme as diretrizes de requisitos previamente definidos (Maximiano, 2002; Valle, Cierco, Soares, \& Finocchio, 2015). Tal esforço, para Shenhar e Dvir (2010) e Kerzner (2011), tem o condão de impulsionar mudanças que são necessárias para o desenvolvimento das organizações. Tradicionalmente, os projetos são planejados e monitorados considerando as variáveis de prazo (cronograma), custos (orçamento) e qualidade (Menezes, 2003).

Segundo o Project Management Institute [PMI] (2017), constituem-se características 
de um projeto: temporalidade, é realizado da maneira que possua um início, meio e fim; individualidade, o projeto se propõe a realizar um trabalho específico; progressividade, composto por sequência de etapas bem delineadas.

As práticas, métodos e ferramentas que são utilizadas na condução dos projetos compõem a disciplina ou área de gestão de projetos, ou seja, o conjunto de metodologias que são aplicados na administração de um projeto, com o escopo de potencializar o alcance de seus requisitos e objetivos (Valle et al., 2015; Borges \& Carvalho, 2011; PMI, 2017).

Entre os inúmeros benefícios de se utilizar as práticas de gestão de projetos, destacamse o uso eficaz de recursos, a racionalização do tempo e dos custos (Luecke, 2010) com uma aproximação maior com clientes, fornecedores e atores-chaves no processo de formação do produto ou serviço (Kerzner, 2006).

Além disso, considerando as diversas práticas de gerenciamento, a gestão de projetos tende a ser mais flexível, pois é adaptativa a vários cenários, podendo ser utilizada em objetivos de qualquer natureza ou complexidade (Vargas, 2005), contribuindo para a desenvolvimento de uma cultura de produtividade e consecução de resultados através da execução das atividades e ações pelo caminho mais direto ou racional (Prado, 2003; Gil \& Silva, 2013).

Diante disso, são constituídas equipes, grupo de pessoas formadas por atores internos ou externos a organização com o objetivo de executar as tarefas relacionadas ao projeto (Rabechini, Carvalho \& Laurindo, 2002). A equipe é composta por indivíduos com papéis e responsabilidades atribuídos, que trabalham coletivamente para alcançar um objetivo em comum de projeto compartilhado (PMI, 2017), que são gerenciados por um ator-chave: o gerente do projeto, cuja incumbência é a condução da equipe para o desenvolvimento dos objetivos do projeto (Patah \& Vargas, 2016).

Desenvolver equipes é o processo de aprimoramento do pessoal do projeto. O PMI (2017) deixa claro que tal processo é contínuo e permanente, ao longo do ciclo de vida do projeto, o que pode promover uma maior motivação da equipe, habilidades aperfeiçoadas e diminuição da rotatividade de pessoal.

Nesse ponto, o guia coloca grande responsabilidade sob a égide do gerente do projeto, que tem o papel de identificar, construir, instruir, manter, motivar, liderar, inspirar e avaliar as equipes do projeto, objetivando o alcance de um desempenho que alicerce o cumprimento dos objetivos do projeto. Sendo assim, percebe-se que o trabalho em equipe é fundamental para o sucesso do projeto (PMI, 2017).

Wefald, Mills, Smith and Downey (2012) ressaltam a ausência de práticas e métodos de como mensurar o engajamento, apesar deste apoio ser crítico para o sucesso do projeto. $\mathrm{O}$ 
engajamento não significa a presença ou aceitação, mas comprometimento com os objetivos do projeto (Peterson, 2013). Martins e Souza (2017) realizaram uma extensa revisão da literatura e não encontraram quaisquer metodologias, técnicas ou ferramentas para mensurar o engajamento. Nos estudos pesquisados, dizem os autores, houve foco apenas nos benefícios e efeitos do engajamento.

Percebe-se, dessa forma, a ausência de perspectiva do engajamento interno dos membros da equipe, dentro da principal publicação sobre gestão de projetos. As pesquisas sobre esse construto remetem quase exclusivamente ao engajamento daqueles que podeminfluenciar o projeto - positiva ou negativamente - e nos financiadores. Isso traz um enfoque para a lacuna que se cria para o engajamento dos membros internos da equipe e propicia um direcionamento para futuras pesquisas na área (Schaufeli \& Taris, 2014).

Matthews et al. (2018) descobriram que projetos com metas e objetivos claros, oportunidades de desafios e aprendizado, autonomia e reconhecimento do esforço dos membros são drivers para o engajamento em equipes de projetos. Por outro lado, a ausênciade desafios, relacionamentos conflitantes e pouco potencial de aprendizagem foram relacionados como fatores negativos para o desligamento dos projetos desses mesmos membros.

Entre os desafios para se implantar uma cultura de gestão de projetos no serviço público, Moutinho, Kniess e Maccari (2013) apontam que a cultura patriarcal, as estruturas organizacionais inflexíveis - muitas vezes limitadas por um complexo sistema de amarras legais - e as resistências culturais são os fatores que podem dificultar o gerenciamento de projetos no serviço público. Alertam os autores ainda sobre a falta de conhecimento sobre o que a gestão de projetos pode agregar à gestão de organizações públicas Moutinho, Kniess \& Maccari, 2013).

\section{Metodologia}

Essa pesquisa buscou escutar os atores e partícipes da ação para então poder detalhar a dinâmica do engajamento em uma equipe de projeto. Em consequência, a pesquisa classifica- se como qualitativa (Creswell, 2007). Quanto ao alcance, essa é descritiva, já que buscou mapear o comportamento entre elementos e o fenômeno principal, descrevendo fenômenos, situações, contextos e eventos (Sampieri, Collado \& Lucio, 2013).

Quanto ao desenho (procedimento), a pesquisa foi realizada em um caso único, ou seja, em um dos projetos de implementação do Parque Tecnológico Metrópole Digital, aproximando esse estudo da estratégia qualitativa denominada estudo de caso. Como 
expediente para aumentar o rigor na análise dos dados, optou-se pela codificação (Sampieri et al., 2013; Yin, 2015).

A primeira fase centrou-se na análise exploratória do tema em pesquisa, através da pesquisa bibliográfica. Após a revisão da literatura, coletou-se os dados (segunda fase) com gerente e membros da equipe de projeto por meio de entrevista semiestruturada individual. Houve uma breve imersão inicial no campo através de entrevista com membros de um projeto-piloto operado pela IFES como forma de se construir o instrumento de coleta de dados. O roteiro foi alinhado aos construtos presentes na revisão da literatura, discutido e validado com os colaboradores que atuaram em projetos institucionais.

As entrevistas tiveram duração aproximada de 25 minutos e foram realizadas em lugar reservado e separado do ambiente de trabalho dos respondentes, garantindo a tranquilidade para que pudessem responder as questões levantadas. Foram realizadas quatro entrevistas. O perfil dos entrevistados é de profissionais de ensino superior completo, femininos e masculinos, que trabalham na IFES. O critério de seleção foi o sorteio de profissionais integrantes da equipe executora do projeto, que continho oito membros. As entrevistas foram transcritas por meio do software QSR NVivo ${ }^{\circledR}$

Após a coleta, partiu-se para a terceira fase da pesquisa, que tratou da análise dos dados. Um híbrido entre a análise de discurso, conteúdo (Sampieri et al., 2013) e a codificação (Charmaz, 2009) facilitou a compreensão dos significados nas narrativas dos membros da equipe do projeto. Em um primeiro momento, não se utilizou conceitos préconcebidos para classificar o conteúdo (Charmaz, 2009). Para gerar os códigos (nós), procedeu-se a codificação aberta frase a frase (ou parágrafo a parágrafo, quando necessário) com auxílio do software QSR NVivo®.

Isso foi feito da seguinte forma: foram extraídos das transcrições alguns trechos das falas que sugeriram a interpretação de fatores que estavam relacionados com o engajamento. Essa análise baseou-se na literatura. Após isso, esses fatores foram mais bem interpretados e categorizados em códigos de análise. Por fim, ouve o cruzamento das falas com os códigos, o que apoio a construção dos diagramas que são apresentados no tópico a seguir. Esse procedimento foi realizado no software QSR NVivo®.

Para facilitar a compreensão, o Quadro 1 é apresentado a seguir, bem como a Figura 1 com a exemplificação da análise dos nós no NVivo®: 


\section{Quadro 1- Processo de codificação}

\begin{tabular}{|l|l|}
\hline Transcrições (dados brutos) & Códigos \\
\hline (...) & \\
Entrevistada 2: No meu caso eu senti. Eu senti. A minha \\
diretoria foi muito, foi muito compreensiva quando eu Reconhecimento da importância do projeto pela \\
precisava me engajar. Então assim, esse reconhecimento, alta gestão \\
ele é muito importante. Assim, até quando foi me confiado \\
isso, foi importante até para eu me sentir... "não, me deram \\
uma tarefa, confiaram em mim, eu vou dar aqui o meuAutorização da chefia imediata para se dedicar ao \\
melhor." Porque né, tá confiando, tá lhe dando um voto deprojeto \\
confiança pra você... trabalhar bem. Então, eu acho que é \\
isso. Eu acho que é o reconhecimento da gestão é \\
fundamental. \\
(...)
\end{tabular}

Fonte: Elaborado pelos autores (2020).

Figura 1: Nós dos Recursos de trabalho

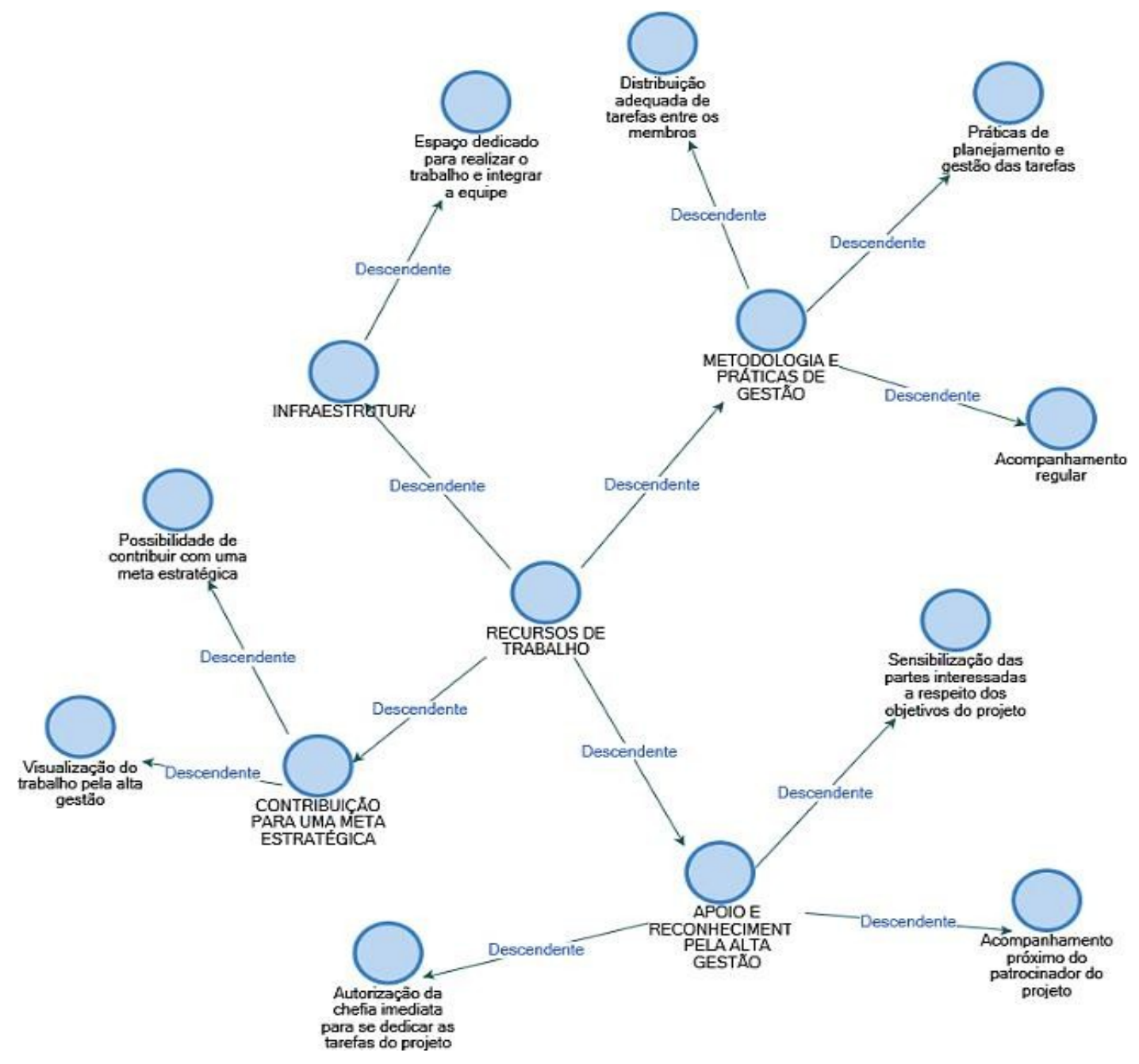

Fonte: Dados da pesquisa/NVivo (2020). 
Chegou-se a um conjunto de 19 códigos, após filtragem e análise dos códigos repetidos. Codificado o material em primeiro nível, o conjunto de categorias e subcategorias foi analisado para encontrar potenciais relações causais, condições intervenientes, contextuais e interações.

A priori, as categorias de análise emergiram do referencial teórico (modelo de demandas e recursos de trabalho, de Schaufeli et al. (2002) e foram constituídas por recursos de trabalho, procurando identificar quais recursos de trabalhos, à luz da teoria de demanda recursos, podem ser usados para aumentar o engajamento; e demandas de trabalho, buscando mapear as principais características ou situações que levariam a exaustão e ao desengajamento. Após isso, o fenômeno principal (engajamento de membros em equipes de projeto) foi representado por meio de uma perspectiva sistêmica, ou seja, por meio de uma estrutura endógena que explicou a causa do fenômeno. Para tanto, utilizou-se a Dinâmica de Sistemas, disciplina que dispõe de diversas ferramentas para compreender sistemas de complexidade dinâmica por meio dos padrões de comportamento entre as estruturas e as partes deste sistema (Sterman, 2000; Bala et al., 2016).

Adotou-se nesta pesquisa os passos metodológicos da Dinâmica de Sistemas baseados nas propostas de Sterman (2000) e Bala et al. (2016) para identificação do problema e modelagem do sistema. O processo de modelagem se concentrou em três primeiros passos da metodologia proposta, não adotando as estruturas de acumulação (estoques) ou de operações algébricas (auxiliares) para gerar simulações.

O primeiro passo foi a definição do problema. Qual problema devemos atacar? Que problema tentamos resolver? Qual o objetivo do modelo? Essas perguntas são realizadas para identificar um propósito claro na construção e simulação do modelo (Sterman, 2000). O segundo passo foi a formulação de pressupostos, ou seja, uma teoria que tenta explicar, previamente, o comportamento do fenômeno pesquisado (Bala et al., 2016). Sterman (2000) cita que a dinâmica de sistemas busca essencialmente explicações endógenas para os fenômenos.

O terceiro passo foi a criação de um diagrama enlace causal. Bala et al. (2016) recomendam que o modelo de simulação deve ser testado precipuamente em um software de modelagem. Desta forma, o software Vensim ${ }^{\circledR}$, apropriado para representar fenômenos dessa natureza, foi utilizado para se construir o diagrama.

$\mathrm{Na}$ modelagem, as unidades de análise provenientes da análise do discurso foram classificadas em variáveis exógenas ou endógenas - que participam do sistema (Sterman, 2000). Em seguida, foram inter-relacionadas tendo como base as narrativas dos entrevistados, resultando em um modelo de natureza qualitativa estruturado em um diagrama de ciclos de 
feedback, de maneira a facilitar a identificação da dinâmica no modelo e as estruturas de enlaces de feedback do sistema modelado.

Um diagrama de enlace causal é uma estrutura que mostra uma relação de causa e consequência entre variáveis. O diagrama, portanto, representa a estrutura de feedback entre duas ou mais variáveis. (Bala et al., 2016). Assim, a construção do modelo obedeceu a notação de Forrester (1994), contendo os elementos necessários para a representação causal do fenômeno, representada a seguir:

Quadro 2 - Notação para representação do fenômeno

\begin{tabular}{|l|l|}
\hline ENGAJAMENTO & Nome do elemento/fator \\
\hline & $\begin{array}{l}\text { Enlace causal positivo (sinal +), ou seja, o crescimento (ou diminuição) da } \\
\text { variável anterior reforça o crescimento (ou diminuição) da variável seguinte. } \\
\text { Ex: "crescimento da variável x aumenta variável y" ou "diminuição da variável } \\
\text { x diminui variável y". }\end{array}$ \\
\hline $\begin{array}{l}\text { Enlace causal negativo (sinal -), ou seja, o crescimento (ou diminuição) da } \\
\text { variável anterior causa a diminuição (ou aumento) da variável seguinte. } \\
\text { Ex: "diminuição da variável x aumenta a variável y" ou "diminuição da } \\
\text { variável x aumenta a variável y". }\end{array}$ \\
\hline
\end{tabular}

Fonte: Elaborado pelos autores (2020).

Neste modelo, enlaces de feedback de reforço e equilíbrio (Sterman. 2000), responsáveis pelo comportamento do sistema, foram identificados, sendo validado posteriormente pelos entrevistados. Buscando dar maior credibilidade à pesquisa, foi adotada uma estratégia de triangulação dos dados, sendo analisadas ainda informações provenientes dos artefatos de acompanhamento e controle dos projetos.

O modelo resultante da dinâmica de engajamento no projeto foi então analisado para se identificar a predominância dos enlaces de feedback ao longo do tempo. Ressalta-se que os recursos pessoais, terceiro elemento do modelo, não foram incluídos na investigação em virtude do recorte realizado, que focou apenas nos aspectos organizacionais que estão relacionados com o engajamento - e não nos aspectos psicológicos internos de cada membro. Para representar a dinâmica do engajamento, buscou-se, no discurso dos entrevistados, como os diversos recursos e demandas atuaram e influenciaram outros fenômenos, especialmente o engajamento.

Cada fator foi referenciado com um código, permitindo que o leitor possa localizar o trecho que corrobora o surgimento do elemento. Antes de realizar a modelagem do sistema, buscou-se mapear o comportamento da performance da equipe. Conhecer o desempenho do 
sistema ao longo do tempo permite aos pesquisadores iniciar o processo de busca dos fatores que causaram aquele comportamento.

\section{Análise e Discussão dos Resultados}

Um diagrama de enlace causal é uma estrutura que mostra uma relação de causa e consequência entre elementos. O diagrama, portanto, representa a estrutura de feedback entre duas ou mais variáveis (Bala et al., 2016). Para validar o comportamento, buscou-se, então, no diálogo dos entrevistados, fatores e relações que pudessem explicar o comportamento do sistema.

A execução de uma maior quantidade de tarefas no início do projeto decorreu do processo de planejamento das tarefas (1.5), ou seja, como as pessoas foram designadas para aquelas tarefas, o pico inicial de quantidade de tarefas executadas está relacionado, precipuamente, com a designação inicial de atividades a serem executadas pelo time. No entanto, os dados demonstram que esse elemento não é o único fator, considerando que só isso não bastaria para garantir a aderência e a participação das pessoas no início do projeto.

\section{Quadro 3 - Trechos das entrevistas}

\begin{tabular}{|l|l|}
\hline Entrevistada 3: Esse primeiro momento aqui, esse primeiro momento ele define é... & Fatores: designação de \\
foi o momento em que cada setor ele ía dizer quais tarefas eles iam ficar & tarefas em virtude do \\
responsáveis em fazer, então, por isso que houve logo essa entrega inicial & planejamento \\
(1.5), com o número de pessoas envolvidas ao longo desse projeto. & \\
\hline
\end{tabular}
(1.5), com o número de pessoas envolvidas ao longo desse projeto.

Fonte: Dados da pesquisa (2020)

Nesse contexto, a possibilidade de participar de um projeto que pudesse contribuir com a construção de uma meta estratégica de grande vulto $(1.2 ; 1.6)$, no caso, a operacionalização de um Parque Tecnológico, contribuiu significativamente para a adesão dos membros no horizonte inicial, o que fica implícito no discurso de uma das entrevistadas.

Naturalmente, a visibilidade que se tem ao participar de um projeto de grande porte acaba por demonstrar o potencial de algumas pessoas para a diretoria da instituição. Participar de um projeto de operacionalização de um Parque Tecnológico traz a possibilidade da instituição (i.e. dos diretores) ver o trabalho dos membros, o que pode aumentar o interesse em participar de um projeto. Nesse sentido, a possibilidade de ser visualizado pela alta gestão (1.4) como um colaborador que está contribuindo para o atingimento de uma meta institucional da organização pode causar um aumento do engajamento. 
Quadro 4 - Trechos das entrevistas

\begin{tabular}{|c|c|}
\hline $\begin{array}{l}\text { Entrevistada } 2: \text { (...) é a possibilidade de uma nova experiência. De uma nova } \\
\text { experiência, de colaborar com algo novo (1.2), trazer coisas novas, e a instituição } \\
\text { vê que a gente... (1.4) não no sentido da gente aprender mais, entende? Ter outra } \\
\text { experiência, trabalhar junto a um Parque, então pra gente... a gente ficava "olha, a } \\
\text { gente, nós vamos também colocar um tijolinho ali no Parque Tecnológico." }\end{array}$ & $\begin{array}{l}\text { Fatores: vontade } \\
\text { de colaborar } \\
\text { com uma meta } \\
\text { estratégica }\end{array}$ \\
\hline $\begin{array}{l}\text { Entrevistada 3: Olha, eu particularmente, eu comecei muito motivada... [entrevistada } \\
\text { usa motivação como sinônimo de engajamento] Por... pela perspectiva de } \\
\text { participar de um projeto que colaborasse para o IMD (1.6), pela proposta do } \\
\text { Parque, então isso foi algo assim que me motivou muito porque é algo assim que eu } \\
\text { almejo ... }\end{array}$ & $\begin{array}{l}\text { Fatores: vontade } \\
\text { de colaborar } \\
\text { com uma meta } \\
\text { estratégica }\end{array}$ \\
\hline
\end{tabular}

Fonte: Dados da pesquisa (2020)

Essa conjuntura, criou, a priori, um pico inicial de crescimento do engajamento e da performance da equipe. Nota-se, entretanto, que não há nenhum ciclo de reforço aqui, já que o comportamento do diagrama $(6.1 ; 7.1$, ver figura 2$)$ aponta para uma queda, o que denota uma grande dependência de fatores exógenos para se criar o engajamento. Os ciclos de reforço fazem com que os sistemas cresçam, ou diminuam, exponencialmente.

Além disso, a possibilidade de vivenciar novas experiências de trabalho (1.7), ou seja, novas práticas e formas de se trabalhar pode constituir um fator de interesse sobre o projeto, o que recai sobre as práticas de gestão, ou seja, a metodologia utilizada para conduzir o projeto. Dessa forma, as utilizações das práticas de gestão parecem ter exercido alguma influência sobre o engajamento.

Quadro 5 - Trechos das entrevistas

\begin{tabular}{|l|l|}
\hline $\begin{array}{l}\text { Entrevistado 1: A parte, no início, eu achei interessante a parte do } \\
\text { planejamento, foi bem interessante a questão do LCC e tal. (1.7) }\end{array}$ & $\begin{array}{l}\text { Fatores: metodologia } \\
\text { / práticas de gestão }\end{array}$ \\
\hline
\end{tabular}
Fonte: Dados da pesquisa (2020)

Após um engajamento inicial, com aumento da performance, os membros começaram a vivenciar dificuldades inerentes a própria execução das atividades do projeto. O primeiro desses problemas é o surgimento de impedimentos das mais diversas ordens (2.1), que podem dificultar a execução e a conclusão das tarefas planejadas. Alguns desses impedimentos são resolvidos, mas em outros há uma maior dificuldade de resolução para o cumprimento da tarefa (2.2), configurando uma dependência de terceiros - agentes externos ao projeto - para concluir as tarefas que lhe foram designadas.

No entanto, considerando o comportamento do sistema (7.1, no diagrama), o ritmo de resolução dos impedimentos foi insuficiente para manter o crescimento do sistema. $\mathrm{Na}$ entrevista de validação, os membros citaram que a dependência de terceiros foi potencializada pelo período sazonal, já que parte dos agentes externos já tinham entrado de férias. 
Quadro 6 - Trechos das entrevistas

\begin{tabular}{|l|l|}
\hline $\begin{array}{l}\text { Entrevistada 3: Então, aí quando você começa a enfrentar os problemas de um } \\
\text { projeto, aí você vai desmotivando assim um pouquinho (2.1), mas aí você se } \\
\text { mantém firme. }\end{array}$ & $\begin{array}{l}\text { Fatores: } \\
\text { surgimento de } \\
\text { impedimentos }\end{array}$ \\
\hline $\begin{array}{l}\text { Entrevistada 3: Bom, como a gente não trabalha isoladamente, eu acho que as vezes } \\
\text { a falta de resposta dos outros acaba também atrapalhando (2.2). }\end{array}$ & $\begin{array}{l}\text { Fatores: } \\
\text { dificuldade de } \\
\text { resolver }\end{array}$ \\
$\begin{array}{l}\text { (...) } \\
\text { Entrevistada 3: Então nem sempre eu tive o feedback que eu queria, que eu } \\
\text { precisava (3.4). Então isso atrapalha... }\end{array}$ & $\begin{array}{l}\text { impedimentos } \\
\text { (...) dependência }\end{array}$ \\
$\begin{array}{l}\text { Entrevistada 3: É, dependência de terceiros. É, quando eu preciso de informação de } \\
\text { outros nem sempre eu tive, então isso acabou atrapalhando [executar as tarefas } \\
\text { do projeto] (3.4). }\end{array}$ & \\
\hline
\end{tabular}

Fonte: Dados da pesquisa (2020)

Dessa forma, os impedimentos tratados tinham dois fluxos: os primeiros, mais fáceis, conseguiam ser resolvidos, mas com certo atraso (representado por duas barras no diagrama), já que, apesar de serem resolvidos, não foram suficientes para manter o crescimento do sistema $(6.1 ; 7.1$, no diagrama). O segundo, composto por impedimentos mais complexos, não conseguiam ser solucionados pela equipe, diminuindo o engajamento. Os dois fluxos criaram dois enlaces causais. Um de crescimento, em que os impedimentos eram resolvidos. O segundo, em que os impedimentos complexos diminuíram o engajamento. Esse tipo é denominado enlace causal de equilíbrio, pois limitam o crescimento do sistema.

Além disso, uma maior performance começa a causar outros problemas nos setores onde os membros trabalham, já que os colaboradores que atuam nesses projetos de melhoria organizacional não são dedicados exclusivamente as tarefas do projeto, o que fazem com que tenham que tentar equilibrar as demandas de tarefas do projeto com as atribuições dos seus cargos $(2.3 ; 2.7 ; 2.8 ; 2.9 ; 2.10 ; 2.11 ; 2.18)$. Isso fica claro no discurso de uma das entrevistas, já que uma maior performance no projeto acaba diminuindo a performance fora dele $(2.4 ; 2.5)$.

A chefia imediata parece ter percebido a diminuição da performance do membro fora do projeto $(2.6 ; 2.4)$, resultando em cobranças para que os membros voltassem a executar as tarefas atinentes as atribuições dos seus cargos. Esse tipo de movimento é natural, pois, segundo um dos entrevistados, se vai para um lado e vai para o outro (2.3), o que pode causar um acúmulo de tarefas em um dos lados e um maior cansaço (2.12).

\section{Quadro 7 - Trechos das entrevistas}

Entrevistada 2: Olha, em alguns momentos eu não senti [liberação da chefia Fatores: pressão para imediata] que isso também acontecia em relação alguns colegas, (...) (2.6) realizar tarefas fora Entrevistada 2: Mas em algumas situações, a gente percebia (...) queixa da gestão do projeto (...). (2.5) 


\begin{tabular}{|c|c|}
\hline $\begin{array}{l}\text { Entrevistado 1: Eu acabei não dando tanta atenção as responsabilidades que } \\
\text { tinha lá, é natural isso, você vai para um lado e vai para o outro. (2.3) }\end{array}$ & $\begin{array}{l}\text { Fatores: acúmulo de } \\
\text { tarefas em um dos } \\
\text { lados (projetos ou } \\
\text { fora do } \\
\text { projeto) }\end{array}$ \\
\hline $\begin{array}{l}\text { Entrevistada 3: Então eu me via assim dividida (2.7). Porque de um lado eu estava } \\
\text { precisando da atenção e do outro lado eu também estava precisando da atenção. }\end{array}$ & $\begin{array}{l}\text { Fatores: diminuição } \\
\text { da performance em } \\
\text { um dos lados } \\
\text { (projeto ou fora do } \\
\text { projeto) }\end{array}$ \\
\hline $\begin{array}{l}\text { Entrevistador: Quando você fala tempo, de que forma? No sentido de conciliar? } \\
\text { Entrevistada 2: Conciliar com as atividades do setor. (2.8) } \\
\text { (...) } \\
\text { Entrevistada 2: As tarefas do projeto e as de fora, no caso, das do setor né? } \\
\text { Cada um tem sua competência, então eu acho que isso daí foi um fator dificultador } \\
\text { (2.9). }\end{array}$ & $\begin{array}{l}\text { Fatores: dificuldade } \\
\text { de conciliar tarefas }\end{array}$ \\
\hline $\begin{array}{l}\text { Entrevistada } 2:(. .) \text { porque muitas vezes pra você cumprir o que é solicitado pelo } \\
\text { projeto, você tinha que tirar um dia, dois, pra... um dia, eu digo assim, um } \\
\text { horário né? (...) porque tem as demandas do outro setor, tem a rotina do setor, e } \\
\text { você parar para fazer as coisas do projeto atrapalhava, um pouco (2.10). E vice- } \\
\text { versa. }\end{array}$ & $\begin{array}{l}\text { Fatores: pressão para } \\
\text { realizar tarefas fora } \\
\text { do projeto }\end{array}$ \\
\hline $\begin{array}{l}\text { Entrevistada } 3 \text { : É porque assim, a gente está participando do projeto, mas } \\
\text { ninguém abandonou as suas funções para participar do projeto. Então a gente } \\
\text { continua com as demandas que a gente tem (...). (2.11). } \\
(\ldots) \\
\text { Entrevistada } 3 \text { : [Isso gera] Em alguns momentos cansaço, né... (2.12) } \\
(\ldots) \\
\text { Entrevistada } 3 \text { : Em alguns momentos, eu tive que dar atenção aos dois lados e } \\
\text { realmente ficou difícil. (...) }(2.13)\end{array}$ & $\begin{array}{l}\text { Fatores: dificuldade } \\
\text { de conciliar tarefas } \\
\text { acúmulo de tarefas } \\
\text { em um dos lados } \\
\text { (projetos ou fora do } \\
\text { projeto) }\end{array}$ \\
\hline $\begin{array}{l}\text { Entrevistada } 3: \mathrm{Na} \text { minha parte, então eu estava começando a desenvolver as } \\
\text { atividades (...) [do projeto] e aí chegou uma demanda no meu trabalho. }(2.22)\end{array}$ & $\begin{array}{l}\text { Fatores: pressão para } \\
\text { realizar tarefas fora } \\
\text { do projeto }\end{array}$ \\
\hline
\end{tabular}

Fonte: Dados da pesquisa (2020)

Além disso, o projeto sofreu com a rotatividade de membros em seu período inicial $(2.19 ; 2.21)$. Os dados demonstram que a falta de conhecimento técnico $(2.14 ; 2.15 ; 2.20)$ para realizar determinadas atividades, tidas como técnicas, ocasionaram um desengajamento de alguns membros (2.14). O período sazonal também foi algo bastante citado, já que iniciar o projeto no final do ano também não auxiliou, já que nesse período as atividades arrefecem, a exemplo da preparação de entregas de relatórios e fechamentos de turmas $(2.16 ; 2.17$; 2.18).

Essa conjuntura possibilitou a criação de um enlace de conciliação de tarefas, ou seja, uma maior performance no projeto diminui a performance fora dele, o que gera uma pressão da chefia imediata para que essas tarefas voltem a ser executadas. Isso causa um desequilíbrio de tarefas dentro e fora, o que diminui o engajamento dentro do projeto e gera um maior acúmulo de tarefas $(2.3 ; 2.13 ; 3.15)$, considerando que nenhuma tarefa foi concluída durante esse período (7.1, no diagrama). Dessa forma, durante a execução, o projeto passou um bimestre sem a conclusão de nenhuma entrega. 
Quadro 8 - Trechos das entrevistas

\begin{tabular}{|c|c|}
\hline $\begin{array}{l}\text { Entrevistado } 1:(\ldots) \text { porque a primeira equipe que foi, estava muito dispersa né, pegou } \\
\text { aquela parte do final de ano, início... algumas pessoas saíram do projeto }(\ldots)(2.19)\end{array}$ & $\begin{array}{l}\text { Fatores: } \\
\text { rotatividade de } \\
\text { membros }\end{array}$ \\
\hline $\begin{array}{l}\text { Entrevistado 1: (...) talvez a dificuldade, a dificuldade logo no início do aprendizado } \\
\text { sobre precificação de serviços, esse tipo de coisa. Eu acho que para alguns } \\
\text { membros do projeto isso foi... assustou um pouco }(\mathbf{2 . 1 4}) . . . \\
\text { (...) } \\
\text { Entrevistado 1: Talvez, no início, as pessoas que estavam na primeira fase do } \\
\text { projeto, talvez, se sentiram desengajados já por conta disso (2.15). } \\
\text { Entrevistado 1: Eu não tenho, eu não sei como fazer isso... é, eu não sei como fazer isso } \\
\text { entendeu? Então algumas pessoas têm um pouco de dificuldade de correr atrás, de } \\
\text { tentar aprender coisas novas, e às vezes se acham incapazes né... (2.20) Então, } \\
\text { talvez lá no início, aí eu não tenho certeza plena, mas eu acho que isso pode ter } \\
\text { influenciado para que as pessoas saíssem da primeira turma lá da primeira } \\
\text { equipe, né... (2.21) }\end{array}$ & $\begin{array}{l}\text { Fatores: } \\
\text { rotatividade de } \\
\text { membros } \\
\text { conhecimento } \\
\text { técnico }\end{array}$ \\
\hline $\begin{array}{l}\text { Entrevistado } 1: \text { (...), a questão das tarefas de final de ano, elas são muito pesadas } \\
\text { né, para as pessoas que estão ali tem muito relatório para entregar e aí isso causou } \\
\text { um desengajamento no início. As férias também, o período de férias (...) (2.16) }\end{array}$ & $\begin{array}{l}\text { Fatores: } \\
\text { dificuldade de } \\
\text { conciliar } \\
\text { tarefas em } \\
\text { virtude do } \\
\text { período } \\
\text { sazonal }\end{array}$ \\
\hline 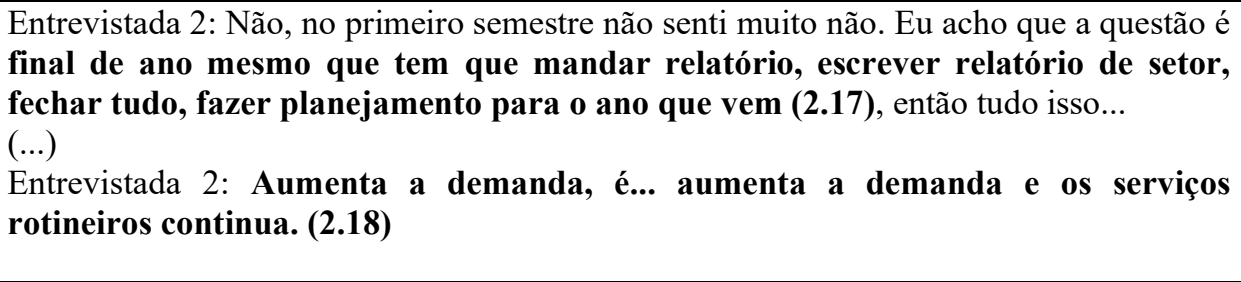 & $\begin{array}{l}\text { Fatores: } \\
\text { dificuldade de } \\
\text { conciliar } \\
\text { tarefas em } \\
\text { virtude do } \\
\text { período } \\
\text { sazonal }\end{array}$ \\
\hline
\end{tabular}

Fonte: Dados da pesquisa (2020)

Apesar de alguns membros não terem apoio de suas chefias, outros conseguiram (3.3; 3.5), o que fez com que a pressão em cima dessas pessoas para realizarem as tarefas do setor diminuíssem e pudessem se dedicar ao projeto (3.4). Além da chefia, houve apoio de outra figura: o patrocinador $(3.9 ; 3.11)$, resolvendo principalmente os impedimentos enfrentados pela equipe (3.6).

Além de sanear as dúvidas dos membros, o patrocinador ainda pode evitar retrabalho da equipe (3.8), pois ele vai ajustando os requisitos do produto para aquilo que é esperado pela alta gestão. Isso gerou um segundo enlace, desta vez de crescimento, ou seja, um maior reconhecimento da chefia imediata e do patrocinador diminuíram a pressão para ter que se dedicar as tarefas fora do projeto, o que diminuiu a pressão e possibilitou um aumento do engajamento. 
Quadro 9 - Trechos das entrevistas

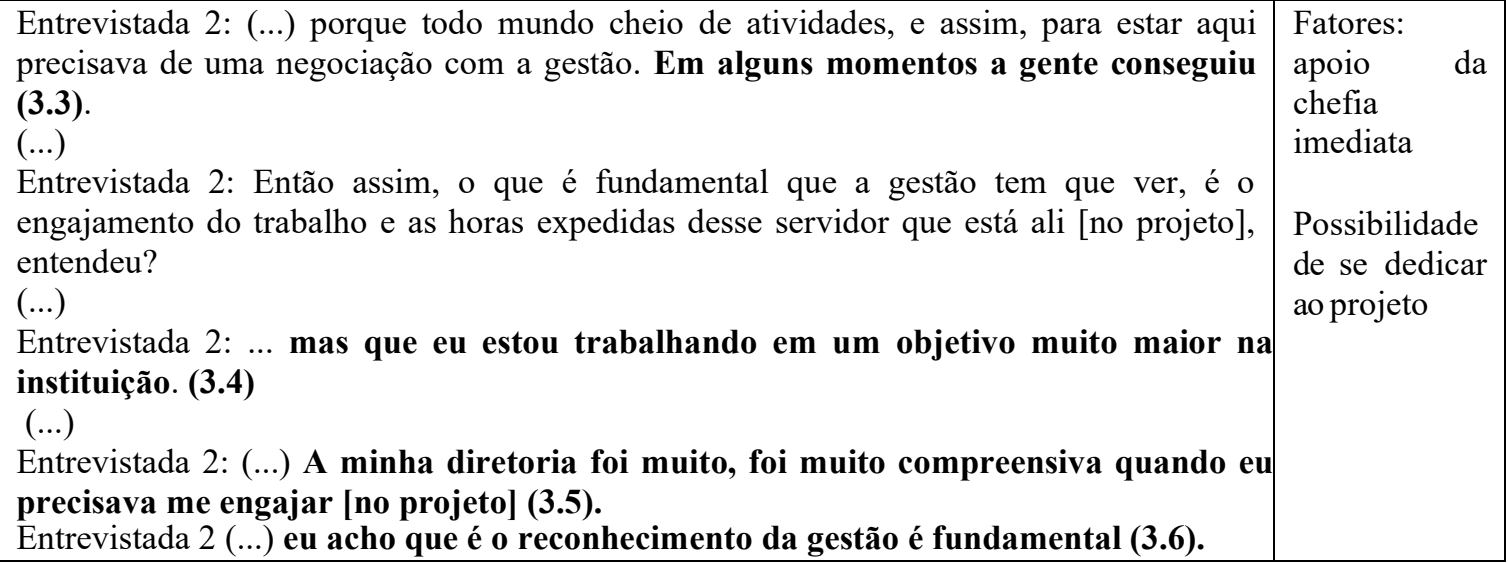

Fonte: Dados da pesquisa (2020)

Com a saída de alguns membros e o período de fim de ano e férias, a performance do projeto caiu $(7.1$, no diagrama, $2.3 ; 2.13 ; 3.15)$ - nenhuma tarefa nesse período foi concluída - ocasionando uma pressão para entregar as tarefas $(3.16 ; 3.18)$, criando um ciclo de equilíbrio para que as tarefas pudessem ser entregues. Com a rotatividade de membros, houve um trabalho inicial de adaptação - para que as novas pessoas compreendessem as práticas de gestão e se sensibilizassem com os objetivos (3.13) -, além do replanejamento das entregas (citado na entrevista de validação), para, só então, as atividades serem reiniciadas (3.17).

\section{Quadro 10 - Trechos das entrevistas}

\begin{tabular}{|l|l|}
\hline Entrevistado 1: A retomada ela é muito custosa (3.16), então... é aí, pronto. Tiveram & $\begin{array}{l}\text { Fatores: } \\
\text { produtividade } \\
\text { mudanças. }\end{array}$ \\
zero (acúmulo de \\
tarefas) \\
Entrevistado $1:$ : Esse período de mudanças é caótico, o engajamento é zero, é \\
praticamente zero (3.15). (...) aí as pessoas começaram a entender melhor o \\
objetivo, a metodologia e... e naturalmente, as pessoas foram engajando mais \\
(3.13). Agente \\
imprimiu um ritmo de reuniões que fez com que nesse período aí de Março até o \\
finalzinho de Abril, dois meses aí, o engajamento foi considerado bom sim \\
(3.14).
\end{tabular}

Fonte: Dados da pesquisa (2020)

A chegada dos novos membros permitiu a criação de um componente afetivoemocional em virtude da assimilação das práticas de gestão $(4.11 ; 4.12)$ e da vivência diária por meio da participação de reuniões, criando um laço efetivo entre o time, unindo a equipe e criando uma rede de engajamento em torno do projeto $(4.13 ; 4.14 ; 4.15)$. Isso criou um 
enlace de crescimento, fazendo com que a performance aumentasse novamente. Nesse período, ocorre a maior parte da execução das atividades, fruto de um esforço conjunto para entrega antes do prazo final do projeto (8.1, no diagrama).

Uma sala dedicada para reuniões e execução dos trabalhos, criada durante esse período, parece também ter auxiliado no processo de conclusão das tarefas (3.12). Dessa forma, com apenas algumas tarefas pendentes no período final (3.19), a performance cai ligeiramente (9.1, no diagrama).

\section{Quadro 11 - Trechos das entrevistas}

\begin{tabular}{|c|c|}
\hline $\begin{array}{l}\text { Entrevistado 1: (...) Porque a primeira equipe que foi, estava muito dispersa né, } \\
\text { pegou aquela parte do final de ano, início... algumas pessoas saíram do projeto e } \\
\text { quando a gente firmou a segunda equipe, que é a atual no caso, a gente } \\
\text { conseguiu nessa sala, no caso de recursos físicos, ter um engajamento maior } \\
\text { das pessoas (3.12). Se mostravam mais interessadas, respondiam em relação } \\
\text { as demandas, então eu acho que são essas duas coisas, esses dois pontos. (4.11) } \\
\text { Entrevistado 1: A questão do ensino da metodologia como vocês passou a } \\
\text { metodologia para a gente foi fundamental para o engajamento (4.12) }\end{array}$ & $\begin{array}{l}\text { Fatores: recursos } \\
\text { físicos } \\
\text { Metodologia aumenta } \\
\text { participação das } \\
\text { pessoas }\end{array}$ \\
\hline $\begin{array}{l}\text { Entrevistada 2: Sim, outra coisa. E tem ai também um elemento fundamental } \\
\text { que é o elemento afetivo, emocional. Que é importantíssimo. Se você não tiver } \\
\text { esse elemento, assim, de acreditar naquilo, de colaborar pra aquilo que você... } \\
\text { para o objetivo funcionar, para aquilo dar certo... Então tem que ter esse } \\
\text { aspecto afetivo, sabe? E isso me ajudou muito durante o processo, na equipe. } \\
\text { Porque assim, a gente era muito alinhado (4.13) ... } \\
\text { (...) } \\
\text { Entrevistada } 2 \text { : É no processo, no dia a dia, nas reuniões, na execução... }\end{array}$ & $\begin{array}{l}\text { Fatores: coesão } \\
\text { grupal }\end{array}$ \\
\hline $\begin{array}{l}\text { Entrevistada 3: Quando se está em uma equipe motivada, isso influencia essa } \\
\text { motivação. (4.14) }\end{array}$ & $\begin{array}{l}\text { Fatores: reverberação } \\
\text { do engajamento }\end{array}$ \\
\hline Entrevistada 3: (...) O engajamento dos outros acaba influenciando & $\begin{array}{l}\text { Fatores: reverberação } \\
\text { do engajamento }\end{array}$ \\
\hline
\end{tabular}

Fonte: Dados da pesquisa (2020)

Após a identificação de cada um dos enlaces causais que formaram a dinâmica do engajamento, representada pelo diagrama a seguir. Ressalta-se que os elementos pontuais foram suprimidos do diagrama, já que a Dinâmica de Sistemas busca encontrar fenômenos que são submetidos a variabilidade ao longo do tempo. Foram encontrados alguns enlaces causais, quais sejam: enlaces de Impedimentos e Resolução De Impedimentos;

\section{Conciliação De Tarefas; Reconhecimento; e Coesão Grupal.}

Foram encontrados ainda dois fatores exógenos, que não participam dos enlaces, mas que exerceram algum tipo de influência durante o ciclo de vida do projeto, sendo que há indícios de que a vontade de contribuir e colaborar com uma meta estratégica parece ter se modificado ao longo do tempo, durante a execução das atividades. Além disso, o conhecimento técnico flutuou ao longo do tempo, ou seja, o conhecimento técnico da equipe era menor no começo e depois aumentou ao longo do período de execução do projeto. 
Figura 2 - Dinâmica do engajamento em uma equipe de projeto

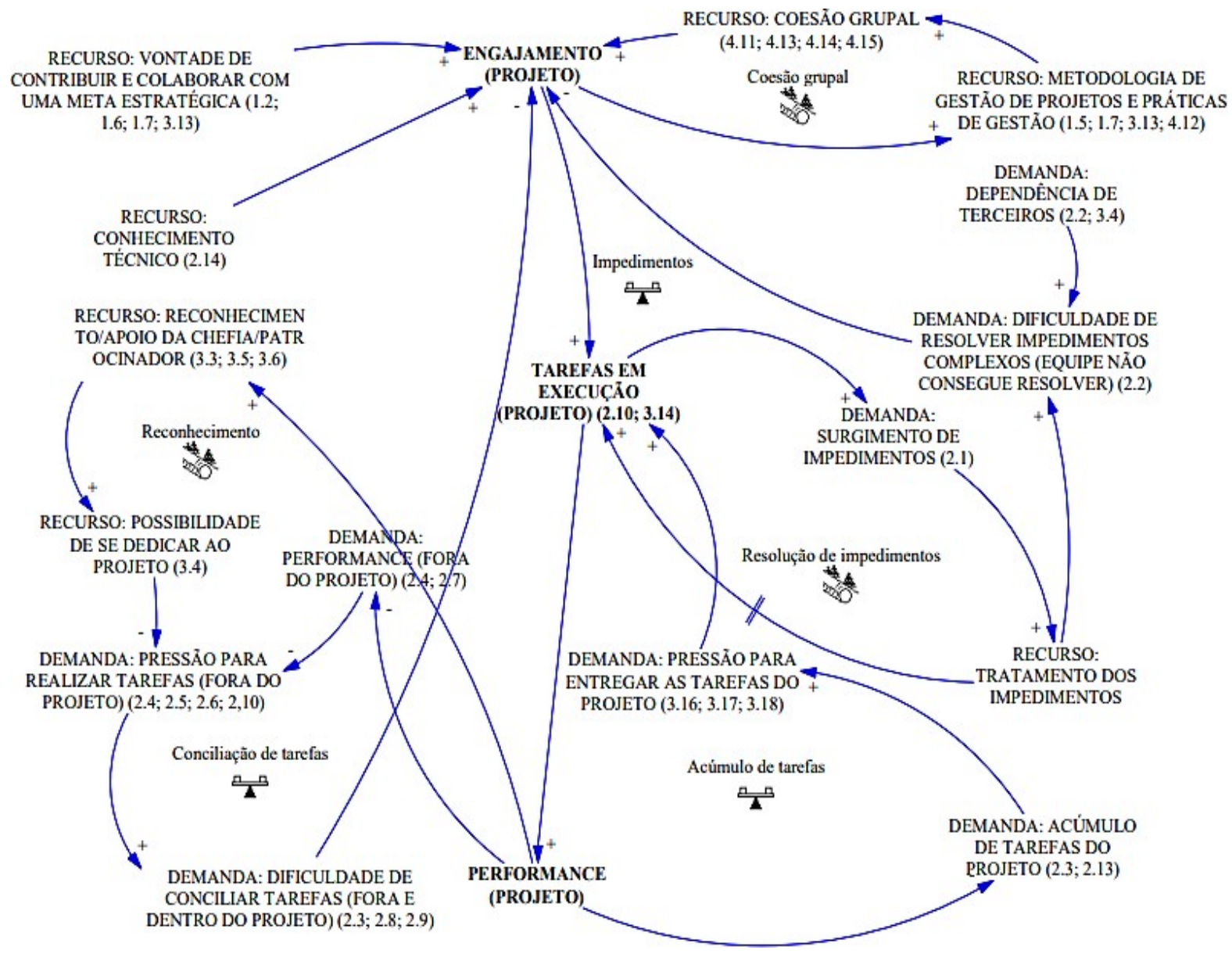

Fonte: Dados da pesquisa (2020)

Em uma primeira análise, o diagrama sugere que a dinâmica do engajamento está relacionada positivamente com a coesão grupal, ou seja, quanto maior o nível de envolvimento da equipe, maior parece ser o engajamento e o reconhecimento do trabalho, quando a organização parece reconhecer o trabalho desenvolvido pelo time. Esse tipo de coesão parece ser proveniente de um sentimento compartilhado entre o time, que habita coletivamente as emoções da equipe (Yang, Chen \& Wang, 2015).

Os resultados sugerem que os recursos de trabalho aumentam o engajamento, refletindo na performance da equipe. As práticas de gestão de projetos exerceram um papel fundamental na conclusão do projeto, operando como recursos de trabalho, alinhado ao modelo de demandas e recursos (Schaufeli et al., 2002). participação efetiva da equipe nas reuniões e na execução das tarefas, dispostos a vencer o prazo, possibilitou também uma forte conexão psicológica, criada no dia a dia do projeto, um verdadeiro estado emergente (Puente-Palacios, 2015), ou seja, percepções coletivas que são compartilhadas pela equipe, gerando unidade e um aumento 
do engajamento, aumentando a colaboração (Bond-Barnard et al.,2018) e o empoderamento da equipe (Tuuli, 2018).

Além disso, aproximar a alta gestão, ou seja, o patrocinador para a equipe do projeto, mostrou-se uma prática exitosa, ao evitar o retrabalho e resolução ágil de impedimentos (Matthews et al., 2018).

Apesar do êxito, o projeto não ficou imune aos problemas, classificados aqui como demandas (Schaufeli et al., 2002). A despeito da conotação negativa, ressalta-se que as demandas não podem ser interpretadas unicamente por esse prisma. A pressão exercida pelo tempo fez com que a performance do projeto aumentasse novamente. Isso está alinhado com o modelo de demandas e recursos, que afirma que a interação entre os recursos e as demandas causam o engajamento.

Contudo, verifica-se que boa parte das demandas atuaram fortemente sob o projeto, dificultando o equilíbrio de tarefas. O balanceamento de atividades, aspecto mais citado pelos entrevistados, parece decorrer de uma crônica dificuldade de delineamento dos processos de trabalho - externos ao projeto -, já que as demandas urgentes - ou seja, atividades que precisam ser realizadas imediatamente - paralisam outras ações. A autonomia para lidar com esses tipos de tarefas pode aumentar o engajamento (Matthews et al., 2018).

A interação entre os recursos e as demandas, conforme prevê o modelo de demandas e recursos, provocam uma resposta que pode ser favorável ou não aos objetivos do projeto, que são ditados pelo patrocinador e a alta gestão. Esses atores são fator-chave no engajamento da equipe, pois podem suavizar o peso das demandas do projeto, por meio do desimpedimento de problemas que os membros podem enfrentar, sensibilização das partes interessadas e disponibilização de recursos que podem ser utilizados pelos membros para executarem as tarefas (Popaitoon \& Siengthai, 2014).

\section{Considerações Finais}

A presente pesquisa objetivou investigar qual a dinâmica do engajamento em equipes de projetos e suas implicações. Dessa forma, utilizou-se uma abordagem interdisciplinar que envolveu o construto psicológico de engajamento, a disciplina de gestão de projetos e a Dinâmica de Sistemas para compreender a dinâmica desse fenômeno no contexto singular de uma equipe de projeto de um Parque Tecnológico, ligado a uma instituição pública.

Com isso, resultados demonstram que os recursos e as demandas são os fatores que estão relacionados com o engajamento, de modo que os recursos parecem suportar o 
engajamento da equipe, enquanto as demandas, oriundas do projeto e das atividades rotineiras da equipe, exercem pressão sobre o engajamento, o que pode diminuir a performance do time. Além disso, contata-se que as práticas de Gestão de projetos influenciam positivamente no engajamento. Ainda assim, o apoio e o reconhecimento da chefia imediata, patrocinador e alta gestão possibilitam que a equipe possa se dedicar ao projeto. Ainda assim, a resolução dos impedimentos e o acúmulo de tarefas diminuem a performance e podem minar o engajamento da equipe.

As limitações enfrentadas no decorrer da pesquisa levam em consideração: desenvolvimento das entrevistas somente com uma equipe de projeto; o não mapeamento dos recursos pessoais, terceiro elemento do modelo de Schaufeli et al. (2002); e uma dificuldade de delimitar o fenômeno estudado.

Por fim, para perspectivas de trabalhos futuros, sugere-se: desenvolvimento de pesquisas em projetos dentro do mesmo ambiente, afim de gerar uma teoria de alcance limitado que possa retratar de maneira mais fidelizada o engajamento das equipes; estudos intercasos e intracasos, investigando outros ambientes e contextos; verificar projetos concluídos com êxito e projetos que não foram concluídos, buscando identificar com os participantes quais fatores levaram aos resultados; e o realização da pesquisa por meio da modelagem hard, ou seja, utilizando fluxos, estoques, auxiliares e operações algébricas para simular o comportamento do sistema.

\section{Referências}

Albrecht, S. L. (Ed.) (2010). Handbook of employee engagement: Perspectives, issues, research and practice. Human Resource Management International Digest, 19(7).

Andersen, E. S., Birchall, D., Jessen, S. A., \& Money, A. H. (2006). Exploring project success. Baltic journal of management, 1(2), 127-147.

Bakker, A. B. (2011). An evidence-based model of work engagement. Current Directions in Psychological Science, 20(4), 265-269.

Bakker, A. B., \& Bal, M. P. (2010). Weekly work engagement and performance: A study among starting teachers. Journal of Occupational and Organizational Psychology, 83(1), 189-206.

Bakker, A. B., \& Demerouti, E. (2007). The job demands-resources model: State of the art. Journal of Managerial Psychology, 22(3), 309-328. 
Bakker, A. B., Demerouti, E., \& Euwema, M. C. (2005). Job resources buffer the impact of job demands on burnout. Journal of Occupational Health Psychology, 10(2), 170-180.

Bakker, A. B., Demerouti, E.; \& Sanz-vergel, A. I. (2014). Burnout and work engagement: The JD-R approach. Annual Review of Organizational Psychology and Organizational Behavior, 1(1), 389-411.

Bala, B., Arshad, F., \& Noh, K. (2016). System Dynamics - Modelling and Simulation. New York: Springer.

Bailey, C., Madden, A., Kerstin, A., \& Fletcher, L. (2017). The meaning, antecedents and outcomes of employee engagement: A narrative synthesis. International Journal of Management Reviews, 19(1), 31-53.

Bond-Barnard, T. J., Fletcher, L., \& Steyn, H. (2018). Linking trust and collaboration in project teams to project management success. International Journal of Managing Projects in Business, 11(2), 432-457.

Borges, J. G., \& Carvalho, M. M. de (2011). Sistemas de indicadores de desempenho em projetos. Revista de Gestão e Projetos-GeP, 2(1), 174-207.

Charmaz, K. (2009). A construção da teoria fundamentada: guia prático para análise qualitativa. Porto Alegre: Bookman.

Cooke-Davies, T. (2002). The "real" success factors on projects. International journal of project management, 20(3), 185-190.

Costa, G. M. (2008). Change management: uma abordagem prática e sistêmica. São Paulo: Nova Prova.

Costa, P. L., Passos, A. M., \& Bakker, A. B. (2014). TeamWork engagement: A model of emergence. Journal of Occupational and Organizational Psychology, 87(2), 414-436.

Creswell, J. W. (2007). Projeto de pesquisa métodos qualitativo, quantitativo e misto. Porto Alegre: Artmed.

Carvalho, M. M. De., Patah, L. A., \& Bido, D. S. de (2015). Project management and its effects on project success: Cross-country and cross-industry comparisons. International Journal of Project Management, 33(7), 1509-1522.

Demerouti, E., Bakker, A. B., Nachreiner, F., \& Schaufeli, W. B. (2001). The job demandsresources model of burnout. Journal of Applied Psychology, 86(3), 499-512

Demerouti, E., \& Bakker, A. B. (2011). The job demands-resources model: Challenges for future research. SA Journal of Industrial Psychology, 37(2), 01-09.

Forrester, J. W. (1994). System dynamics, systems thinking, and soft OR. System dynamics review, 10(2-3), 245-256. 
Gil, A. C., \& Silva, E. C. (2013). Inovação e gestão de projetos: os "fins justificam os “meios”. Revista de Gestão e Projetos, 4(1), 138-164.

Gkorezis, P., Bellou, V., Xanthopoulou, D., Bakker, A. B., \& Tsiftsis, A. (2016). Linking football team performance to fans' work engagement and job performance: Test of a spillover model. Journal of Occupational and Organizational Psychology, 89(4), 791812.

Grover, S. L., Teo, S. T. T., Pick, D., \& Roche, M. (2017). Mindfulness as a personal resource to reduce work stress in the job demands-resources model. Stress and Health, 33(4), 426436.

Han, S. J., \& Beyerlein, M. (2014). Managing culturally diverse virtual teams: A systematic literature review., Texas A\&M University.

Henderson, L. S., Stackman, R. W., \& Lindekilde, R. (2016). The centrality of communication norm alignment, role clarity, and trust in global project teams. International Journal of Project Management, 34(8), 1717-1730.

Hsu, J. S. C., Li, Y., \& Sun, H. (2017). Exploring the interaction between vertical and shared leadership in information systems development projects. International Journal of Project Management, 35(8), 1557-1572.

Ilgen, D. R., \& Hollenbeck, J. R. (1991). The structure of work: Job design and roles. In M. D. Dunnette \& L. M. Hough (Eds.). Handbook of industrial and organizational psychology (Vol. 2, Chap. 3, pp. 165-207). Mountain View: Davies-Black.

Kerzner, H. (2006). Gerenciamento de Projetos: uma abordagem sistêmica para planejamento, programação e controle. Porto Alegre: Bookman.

Kerzner, H. (2011). Gerenciamento de Projetos: uma abordagem sistêmica para planejamento, programação e controle. São Paulo: Blucher.

Koyuncu, M., Burke, R. J., \& Fiksenbaum, L. (2006). Work engagement among women managers and professionals in a Turkish bank: Potential antecedents and consequences. Equal Opportunities International, 25(4), 299-310.

Leiter, M. P., \& Bakker, A. B. (2010). Work engagement: A handbook of essential theory and research. Hove: Psychology press.

Lewig, K. A., Xanthopoulou, D., Bakker, A. B., Dollard, M. F., \& Metzer, J. C. (2007). Burnout and connectedness among Australian volunteers: a test of the Job DemandsResources model. Journal of vocational behavior, 71(3), 429-445.

Liu, W. H., \& Cross, J. A. (2016). A comprehensive model of project team technical performance. International Journal of Project Management, 34(7), 1150-1166. 
Luecke, R. (2010). Gerenciando projetos grandes e pequenos. Rio de Janeiro: Record.

Lyons, P. (2008). The crafting of jobs and individual differences. Journal of Business and Psychology, 23(1-2), 25-36.

Macey, W. H., \& Schneider, B. (2008). The meaning of employee engagement. Industrial and organizational Psychology, 1(1), 3-30.

Martins, E. G. P., \& Souza, J. Neto (2017). Mensuração do Engajamento das Partes Interessadas em Projeto na Visão do Gerente de Projeto e das Próprias Partes Interessadas. Revista de Gestão e Projetos, 8(1), 42-56.

Matthews, J., Stanley, T., \& Davidson, P. (2018). Human factors and project challenges influencing employee engagement in a project-based organization (PBO). International Journal of Managing Projects in Business, 11(4), 873-885.

Maximiano, A. C. (2002). Administração de projetos. São Paulo: Atlas.

Mcclelland, G. P., Leach, D. J., Clegg, C. W., \& Mcgowan, I. (2014). Collaborative crafting in call centre teams. Journal of Occupational and Organizational Psychology, 87(3), 464-486.

Menezes, L. C. de M. (2003). Gestão de Projetos. São Paulo: Atlas.

Moutinho, J. da, A., Kniess, C. T., \& Maccari, E. A. (2013). A influência da gestão de projetos na estratégia de transferências voluntárias de recursos da União para municípios brasileiros: o caso de uma prefeitura de médio porte. Revista Ibero Americana de Estratégia, 12(1), 181-207.

Patah, L. A., Vargas, D. M. Neto (2016). Avaliação da Relação entre a Virtualidade de Equipes e o Desempenho Operacional de Projetos: uma Análise Quantitativa. Revista de Gestão e Projetos, 7(2), 54-74.

Peterson, H. C. (2013). Fundamental principles of managing multi-stakeholder engagement. International Food and Agribusiness Management Review. Michigan, 16(A), 11-22.

Project Management Institute (2017). A guide to the project management body of knowledge (PMBOK® guide) (6th ed.). Newtown Square: Project Management Institute.

Popaitoon, S., \& Siengthai, S. (2014). The moderating effect of human resource management practices on the relationship between knowledge absorptive capacity and project performance in project-oriented companies. International Journal of Project Management, 32(6), 908-920.

Prado, D. (2003). Gerenciamento de projetos nas organizações. Belo Horizonte: Desenvolvimento Gerencial. 
Puente-palacios, K. (2015). Grupos e Equipes. In P. Bendassolli \& J. E. Borges-Andrade (Eds.). Dicionário de Psicologia do Trabalho e das Organizações (pp. 381-391). São Paulo: Casa do Psicólogo.

Quiñones, M., Broeck, A. van den, \& Witte, H. de (2013). Do job resources affect work engagement via psychological empowerment? A mediation analysis. Revista de Psicología del Trabajo y de las Organizaciones, 29(3), 127-134.

Rabechini, R. Jr., Carvalho, M. M., \& Laurindo. F. G. B. (2002). Fatores críticos para implementação de gerenciamento por projetos: o caso de uma organização de pesquisa. Revista Produção, 12(2), 28-41.

Reijseger, G., Schaufeli, W. B., Peeters, M. C. W., Taris, T. W., Beek, I. van, \& Ouweneel, E. (2013). Watching the paint dry at work: Psychometric examination of the Dutch Boredom Scale. Anxiety, Stress \& Coping, 26(5), 508-525.

Richardsen, A. M., Burke, R. J., \& Martinussen, M. (2006). Work and health outcomes among police officers: The mediating role of police cynicism and engagement. International Journal of Stress Management, 13(4), 555-574.

Salanova, M., Agut, S., \& Peiró, J. M. (2005). Linking organizational resources and work engagement to employee performance and customer loyalty: the mediation of service climate. Journal of applied Psychology, 90(6), 1217-1227.

Salas, E., Dickinson, T. L., Converse, S. A., \& Tannenbaum, S. I. (1992). Toward an understanding of team performance and training. In R. W. Swezey \& E. Salas (Eds.). Teams: Their training and performance (pp. 3-29). New York: Ablex Publishing.

Sampieri, R. H., Collado, C. F., \& Lucio, P. B. (2013). Metodologia de pesquisa (5a ed.). Porto Alegre: Penso.

Schaufeli, W. B.; Bakker, A. B. (2003). Utrecht work engagement scale: Preliminary Manual (Vol. 1). Utrecht: Utrecht University.

Schaufeli, W. B., Salanova, M., González-romá, V., \& Bakker, A. B. (2002). The measurement of engagement and burnout: A two sample confirmatory factor analytic approach. Journal of Happiness studies, 3(1), 71-92.

Schaufeli, W. B., \& Taris, T. W. (2014). A critical review of the Job Demands-Resources Model: Implications for improving work and health. In G. F. Bauer \& O. Hämmig (Orgs.). Bridging occupational, organizational and public health (Chap. 4, pp. 43-68). New York: Springer.

Shenhar, A., \& Dvir, D. (2010). Reinventando gerenciamento de projetos: a abordagem diamante ao crescimento e inovação bem-sucedidos. Harvard: M. Books. 
Shuck, M. B., Rocco, T. S., \& Albornoz, C. A. (2011). Exploring employee engagement from the employee perspective: Implications for HRD. Journal of European Industrial Training, 35(4), 300- 325.

Shuck, B., Reio, T. G. Jr., \& Rocco, T. S. (2011). Employee engagement: An examination of antecedent and outcome variables. Human resource development international, 14(4), 427-445.

Sterman, J. D. (2000). Business dynamics: system, thinking and modeling for a complex world. New York: McGraw Hill.

Tuuli, M. M. (2018). What has project characteristics got to do with the empowerment of individuals, teams and organizations. International Journal of Managing Projects in Business, 11(3), 708-733

Valle, A. B. Do., Cierco, A. A., Soares, C. A. P, \& Finocchio, J. Jr. (2015). Fundamentos do gerenciamento de projetos. Rio de Janeiro: FGV.

Vargas. R. (2005). Gerenciamento de projetos: estabelecendo diferenciais competitivos (9a ed.). Rio de Janeiro: Brasport.

Wefald, A. D., Mills, A. J., Smith, M.R., \& Downey, R. G. (2012). A Comparison of Three Job Engagement Measures: Examining their Factorial and Criterion- Related Validity. Applied Psychology: Health and Well-Being, 4(1), 67-90.

Xanthopoulou, D., Bakker, A. B., Demerouti, E., \& Schaufeli, W. B. (2007). The role of personal resources in the job demands-resources model. International journal of stress management, 14(2), 121-141.

Yang, L. R., Chen, J. H., \& Wang, X. L. (2015). Assessing the effect of requirement definition and management on performance outcomes: Role of interpersonal conflict, product advantage and project type. International Journal of Project Management, 33(1), 67-80.

Yin, R. K. (2015). Estudo de Caso: Planejamento e Métodos (5a ed.). Porto Alegre: Book.

Submetido em: 19.01.2021

Aceito em: $\quad 08.02 .2021$ 